\title{
Bridging the rationalist-constructivist divide: re-engineering the culture of the World Bank
}

\author{
Daniel L. Nielson ${ }^{\mathrm{a}}$, Michael J. Tierney ${ }^{\mathrm{b}}$ and Catherine E. Weaver ${ }^{\mathrm{c}}$ \\ ${ }^{a}$ Department of Political Science, Brigham Young University, 745 SWKT, Provo, UT 84602, USA. \\ E-mail: daniel_nielson@byu.edu \\ ${ }^{\mathrm{b}}$ Department of Government, College of William and Mary, Box 8795, Williamsburg, \\ VA 23187-8795, USA. \\ E-mail: mjtier@wm.edu \\ ${ }^{\mathrm{c}}$ Department of Political Science, University of Kansas, 1541 Liliac Lane, Lawrence, KS 66044, \\ USA. \\ E-mail: cweaver@ku.edu
}

In this article, we seek to explain reform patterns at the World Bank. Traditional realist and institutionalist theories say little about the process of change within international organizations ('IOs'). Drawing upon the insights of relatively new rationalist and constructivist approaches, we develop and test a model of IO change that combines insights from rationalism and constructivism. Our explanation integrates the 'top-down' logic of a rationalist principal-agent model - targeting the redesign of organizational structures, hiring procedures and promotional standards, and the 'bottom-up' logic of sociological constructivism - focusing on the transformation of bureaucratic culture. We find that reform outcomes hinge upon the ability of change entrepreneurs to disrupt both the logics of consequence and appropriateness that shape the preferences and behaviour of bureaucratic actors. We evaluate our model by examining four distinct aspects of the World Bank's Strategic Compact (1997-2001), which included attempts to alter project management, organizational culture, and the mission of the institution itself.

Journal of International Relations and Development (2006) 9, 107-139. doi:10.1057/palgrave.jird.1800084

Keywords: constructivism; international organizations; organizational culture; rationalism; World Bank

\section{Introduction}

At the age of 60 , the World Bank has been suffering a mid-life crisis for over a decade. ${ }^{1}$ During this period, the Bank has faced the growing wrath of nongovernmental organizations (NGOs), civil society groups and its own member states, all of whom denounce the Bank for sidestepping its own policies and falling far short of its goal of alleviating world poverty. To appease its many critics in an era of mounting development challenges and declining aid, the 
World Bank has become 'overstretched and under-loved' (Wilks 2001). Consequently, the Bank has developed a nasty case of mission creep, faced conflicting demands for organizational reform, and experienced a dramatic decline in the morale of its staff (Einhorn 2001). It is clear to many observers that the Bank must be fundamentally reformed, reinvented or simply eliminated (Pincus and Winters 2002). Within the Bank today, staff members anticipate with great trepidation and cynicism the 'next big reorganization' under the new leadership of President Paul Wolfowitz, who has already signalled his desire for management reform at the Bank (Einhorn 2006). ${ }^{2}$

Dramatic bureaucratic reforms in the face of public criticism are common in the Bank's history. ${ }^{3}$ The latest reform effort was launched by the charismatic and ambitious President James Wolfensohn in 1996. Entitled the 'Strategic Compact', it was a 4-year programme to re-engineer the Bank's entire organizational hierarchy and incentive structure in the hope of fundamentally transforming the way the development organization does - and is perceived to do - its business. At the end of the reform period, however, the results were quite mixed. Many critics depicted the reform as a 'smoke and mirrors' act, with a dramatic transformation in the Bank's rhetoric and little change in its underlying development ideology or the operational behaviour of its staff. Others applauded the 'new' World Bank. Within the organization, staff suffered from 'change fatigue' and widespread cynicism. Post hoc evaluations of the reform programme revealed mixed results. While reform clearly succeeded in changing organizational behaviour in some target areas, it fell far short or even backfired in others.

We argue that organizational reform can be fruitfully analysed from both sides of the 'rationalist-constructivist divide'. However, the elaboration of a generalizable model of international organization (IO) change requires that we specify the conditions in which each approach is most useful and how they might be combined in a coherent way. Along these lines, we suggest one plausible strategy for an empirical synthesis of these allegedly incompatible approaches to the study of IOs. Like Fearon and Wendt (2002), we conceive of rationalism and constructivism as complements rather than competitors. ${ }^{4} \mathrm{We}$ focus specifically on changes to organizational incentives and norms, focusing on the mechanisms through which the Bank's organizational culture is transformed and, by extension, the preferences and behaviour of Bank staff members.

This case presents a puzzle for nascent theories of IO change. Recent constructivist work, representing the application of sociological organizational theory to IOs, suggests that IOs with a deeply rooted bureaucratic culture are difficult to change and that such change will be incremental and path dependent when it comes (Barnett and Finnemore 2004; Leiteritz 2005; Momani 2005; Weaver 2005). ${ }^{5}$ Kofi Annan's remark that 'revolutions do not 
flourish in the UN' seems equally applicable to the World Bank. Yet, in many core areas of the Bank we observe significant reform in the direction demanded by Wolfensohn and his management team. Rationalist principal-agent (PA) theory predicts that IO staff will respond quickly to principal (management) demands so long as the principals possess information about agent (staff) behaviour and policy outcomes that allows them to re-design staff incentives and mechanisms of control. Wolfensohn and his reform team did just this. Nonetheless, there are identifiable patterns of staff behaviour that continue as before despite the fact that they were targeted from the top. Intensive efforts to induce deeper transformations sometimes foundered in the face of entrenched organizational routines and culture. Stand-alone constructivist and rationalist approaches are at a loss to explain these mixed outcomes.

Seeking to explain patterns of behavioural change at the Bank, we draw from both rationalist (PA) and constructivist (organizational sociology) approaches. We focus on both strategic and principled behaviour within the Bank's bureaucracy: the changes to the incentives and norms shaping the preferences and behaviour of Bank staff members, with specific attention given to the influence and dynamics of the organizational culture. We define organizational culture here as the shared ideologies, norms, and routines that shape staff members' expectations about how agendas are set, mandates are operationalized, projects are implemented and evaluated, and what staff behaviour will be rewarded or punished in promotions and demotions. Organizational culture also influences the worldview of Bank staff, shaping the way they understand the meaning of 'development' and the role or identity of the Bank in promoting development. Likewise, organizational culture affects how Bank staff responds to or proactively engage the demands and pressures in their external authorizing and task environment. Organizational culture is far from monolithic in the Bank and internal debate thrives. Nevertheless, even dissenting staff members recognize and describe with surprising consistency a distinct dominant culture within the Bank. This culture is characterized by neoliberal economic theory, a technocratic approach to problems, and apolitical norms that shape the way the Bank staff collectively think about development. In its operational policy, the Bank is characterized by its Washington-centric approval culture and a disbursement imperative that drive the way it pursues development aid. In sum, it is a culture that has been widely vilified and thus targeted for change in repeated Bank reorganizations.

Indeed, transforming the Bank's culture was a primary objective of the Compact reform architects, with the clear expectation that a cultural shift could be engineered to change the behaviour of Bank management and staff. Yet, how do we understand the role of culture in the process and outcomes of IO change (Leiteritz 2005)? Derived from sociology, constructivist theory suggests that organizational culture inhibits the reform that necessitates the 
fundamental disruption of staff members' 'mental models' (Schein 1992; Barnett and Finnemore 2004). Over time, individuals become partially socialized into their bureaucratic environment. Their strategies or choice sets are constrained as they internalize particular logics of appropriateness and come to accept particular causal beliefs about the world that are strongly influenced by their bureaucratic environment. ${ }^{6}$ The rational behaviour of staff is thus both bounded and socially constructed by the organizational culture. Of course, individuals are neither pure creatures of habit nor cultural 'dupes'. Instead, they maintain the cognitive ability to recognize culture for what it is and resist it (Swidler 1986; Barnett and Finnemore 1999).

Those individuals seeking to change the collective behaviour of an organization (often a new management team) may strategically engage culture towards their ends. These reformers or 'norm entrepreneurs' do so by couching change goals in ways that do not appear 'counter-hegemonic' but which are instead culturally compatible. In other words, they articulate new ideas and goals and fit new incentives to existing norms in ways that do not require current staff to wholly discard their pre-existing worldviews or behavioural habits. Changing IOs thus becomes in part a matter of re-engineering the organizational culture.

We propose that these principal-induced attempts at organizational reform, instigated via internal change entrepreneurs, will succeed chiefly where the resulting behaviours and organizational outcomes are measurable (and thus information is more symmetric and deviant behaviour is easily identifiable), and where the proposed reforms are adjacent to existing norms (i.e. they 'fit' within the existing culture). To articulate this claim, we develop a two-stage model based on the sequencing of agency and organizational theories ${ }^{7}$ wherein organizational culture is both the target of change by rational principals as well as an independent factor constraining or enabling the accomplishment of specific reform goals.

In the following section, we develop this argument by presenting both the competing and complementary versions of a rationalist and constructivist model of IO change. To empirically test our proposed model, we investigate behavioural change at the Bank during the period of the Strategic Compact reform initiative (1997-2001). After briefly describing the initiative, we examine the gaps between the reform goals and actual behavioural outcomes across major areas of the Compact initiative. Here, we seek to distinguish between those aspects of these reforms that target changes in formal structures and operations and those that aim for changes in the shared ideas, norms, and patterns of interaction (or 'habits') that comprise the Bank's organizational culture. To capture the degree of change within specific thematic areas of the Strategic Compact, we employ data gathered from the official evaluations of the Compact (conducted in late 2001), a new database of World Bank loans, 
and more than 30 interviews of Bank management and staff in Washington, DC and in field offices.

\section{Theorizing IO Change}

When can organizational reformers target incentive structures and the underlying organizational culture to incite a change in bureaucratic behaviour, and when are their efforts thwarted? The rationalist thesis, embodied in PA theory, relies upon a 'logic of consequences' and suggests that organizational behaviour changes chiefly when material incentives for the employee are altered. In other words, compensation and reward structures shape organizational behaviour and outcomes: if principals (in this case the organizational leadership of the President and senior management of the Bank) can control incentive structures, then agents (IO staff) should consistently do the principals' bidding. The World Bank is ultimately responsible to its member states who authorize the allocation of development assistance through a long chain of delegation that runs from citizens to politicians to their representatives on the Executive Board to Management to the Bank staff (and often to private contractors or NGOs). A number of links in this chain of delegation have been individually analysed using PA theory (Cooley and Ron 2002; Martens 2002; Nielson and Tierney 2003, 2005); however, we focus our attention in this article on an under-explored link in this chain that is represented as link 2 in the Figure 1 below. During the Strategic Compact reform, the crucial action took place at this link and manifested as a conflict between senior management and staff (Mallaby 2004).

Any principal's ability to re-engineer agent behaviour through incentive restructuring, however, is conditioned by asymmetric information (Kiewiet and McCubbins 1991; Lupia and McCubbins 1998; Koremenos et al. 2001). ${ }^{8}$ Agents can hide their actions from principals and can conceal other information that might enhance the ability of principals to observe and sanction deviant behaviour. Thus, information asymmetries increase agents' (the staff's) ability to shirk their duties or pursue behaviour unintended by their principals (management).

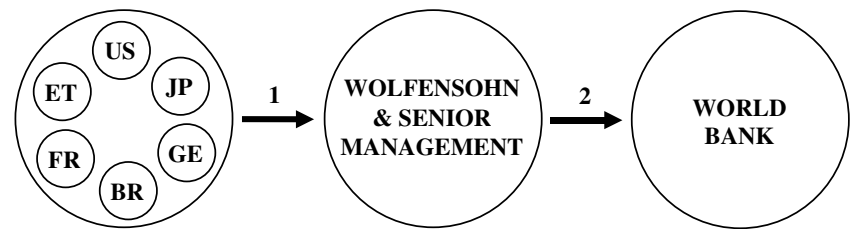

Figure 1 The delegation chain at the World Bank. 
Yet, principals are far from powerless in this relationship. Besides drafting contracts, principals can carefully screen and select agents as they hire and promote them. Principals can monitor agents directly or indirectly by enlisting the aid of third parties. Principals can also design administrative checks and procedures that empower and motivate additional agents to check the actions of the primary agents or that require the production of information useful to the principal (Kiewiet and McCubbins 1991; Nielson and Tierney 2003).

From these insights, we derive the central PA hypothesis for this article: the gaps between principal preferences and agent actions will shrink as the quantity and quality of information about agent actions grows and improves, and thus change (in the desired direction) is more likely when these information asymmetries are resolved. In this instance, organizational reformers can successfully manipulate the underlying incentive structures to redefine staff expectations and thus direct behavioural change. When agent actions are difficult to monitor, gaps should grow. Thus, if the categories of the Bank's Compact reform programme vary in terms of the ability of Wolfensohn and his reform team to monitor and consistently reward or sanction staff members' behaviour in achieving (or not) a mandated goal, then the size of the gaps should diverge concomitantly. We expect that the Compact categories where staff behaviour is most easily measured should see the greatest reduction in gaps between the Compact's stated goals in 1996 and the Bank staff's behaviour in 2001. The categories of the Compact where goals are more abstract and less measurable should see less behavioural change. Here, we define measurability as the degree to which staff actions or policy outcomes can be categorized, quantified, and verified independently. This last component, verifiability, means that principals have independent access to sources of information about the agents' behaviour beyond the information supplied by the agents themselves (Lake and McCubbins 2006). When such quantification and verification is difficult or costly, larger gaps should persist.

Constructivist approaches based on sociological theory present a different perspective on IO change. Here, institutional reform is characterized by a transformation in ideologies, norms and appropriate standards of behaviour (Barnett and Finnemore 2004). Every bureaucratic organization has a particular culture comprised of 'basic assumptions' or shared ideas about an organizational mission, routinized patterns of interaction, and standard operating procedures that individuals in the organization use to interpret information and demands from their surroundings (Schein 1992). Individuals who share this culture make their decisions - strategically or habitually depending on their degree of socialization into the institution - based on this jointly created view of the world and their organization's place in it. Organizational culture accretes over time as members of the organization establish these regularized patterns and their common language. 
Bureaucratic culture, once entrenched, can be highly stable and robust. ${ }^{9}$ Formal institutions can be altered, individual personnel come and go, but change in organizational culture is typically glacial (Kapur 2000). The presumption here is that staff will naturally be resistant to change driven from outside the organization or from the top levels of management that requires a dramatic change in culture. ${ }^{10}$ Indeed, the cultural change envisioned in the Strategic Compact requires a significant shift in ideologies, shared norms, and expectations about appropriate patterns of interaction. Such change is inherently slow, requiring staff to dismiss pre-existing beliefs and habits and 'learn' new behaviour (Haas and Haas 1995). As such, staff working within a cultural environment that clashes strongly with the new demands of its principals may not respond immediately or perfectly to these 'marching orders'. Proposed changes to organizational culture - or new norms - may even be met with overt resistance and hostility (especially by those who thrive in the existing culture). Or worse, individuals within the organization might simply ignore attempts at cultural change because they cannot process the new ideas within their current horizon of understanding.

Yet, despite its perceived inertia, organizational culture can be altered through adaptation and learning (Haas 1990). But it usually takes a concerted effort by 'norm entrepreneurs' within and outside the organization who engage in key debates that, albeit slowly, alter the underlying ideologies, linguistic discourses, and operational norms that shape organizational behaviour (Finnemore and Sikkink 1998). As a result, institutional change will most likely occur when the proposed changes dovetail cleanly with the existing organizational norms in a way that modifies without critically challenging existing cultural ideologies and norms. ${ }^{11}$

From this insight of organizational theory, the following constructivist hypothesis flows: gaps between principals' preferences and agent behaviour will shrink to the degree that new norms and ideas are 'adjacent' to the prevailing culture (Finnemore and Sikkink 1998). In other words, organizational reforms that require incremental shifts or small adaptations in deeply embedded ideologies, norms, and routines are far more likely to succeed than reforms that evoke cognitive dissonance or attempt to displace existing logics of appropriateness with something radically new.

PA models and constructivist theory therefore have differing views on the role of culture in organizational change. When pressed, rationalists typically posit that the norms which constitute culture are not unlike the rules that characterize more formal institutions - culture is just less formal and explicit. Altering the normative incentives for actors should not appreciably differ from altering the institutional incentives. But the success of organizational culture change should similarly hinge on the quantity and quality of the information that principals possess about the norms themselves and the agents' response to 
them. Culture, to the degree it matters, should prove reasonably malleable. Like other institutions and outcomes, culture is chosen and thus subject to conscious efforts at redesign.

For their part, constructivists scoff at such an analytical overstretch on the part of rationalists. Culture cannot be easily manipulated, even by highly motivated and powerful principals. Instead, cultural change occurs chiefly where members, in an ongoing, dynamic and participatory process, contest and debate the prevailing norms in an attempt to change them - a process of communicative action that nonetheless takes place within an environment that already privileges certain language, theories, and methods (Bebbington et al. 2004; Leiteritz 2005). Cultural change is almost always slow and path dependent.

This brings us to our core synthetic insight. Reformers likely understand that organizational culture matters and that it can be changed most effectively where persuasive argument finds points of convergence with existing organizational norms. Thus, organizational leaders may change the personnel and organizational structures as well as design measurable career incentives in order to enable and encourage the organization's staff members to learn and internalize new norms and values - that is, to change the organizational culture. We can conceive several mechanisms through which new norms, ideas, and values might be internalized. First, by hiring personnel who share their own 'new' values (i.e. install or promote 'change entrepreneurs') and firing oldguard 'cultural traditionalists', principals can shift the median ideational position of the organization as a whole in their preferred direction. Second, principals can hire instructors and spend more money on training and education with an eye toward inculcating certain norms, values, and ideas. Third, and arguably most important, changing the personnel within an organization and forcing work-related contact between new and old staff members can catalyse norm-changing debate and encourage the adoption of new ideas through direct exposure to these norm entrepreneurs. ${ }^{12}$ However, this mechanism is subject to the same agency and constructivist theory logic stipulated above. Such principal-induced cultural change will likely succeed primarily where behaviours associated with the desired changes - engagement in debate over cultural change, training sessions, and the inclusion of norm entrepreneurs - are measurable and verifiable and where the proposed new norms are adjacent to the prevailing organizational norms (Figure 2).

Thus, our suspicion is that the alternative hypotheses derived from agency and organizational theory alone will fail to predict the contours of organizational change within IOs. Both predict (relatively intuitively) change under the specified conditions of observability and adjacency. But neither theory alone fully captures the causal process at work. Staff members do not merely learn, they are sometimes schooled - both by their principals and 




Figure 2 Explaining PA gaps in IOs.

by persuasive co-workers. These co-workers are sometimes motivated by more 'appropriate' norms, but other times they enter the organization - in fact, are specifically chosen by principals — because they already possess particular beliefs that are consistent with the new goals of their reform-minded principals.

Thus, in the spirit of bridge-building in the study of international relations, we set aside the ontological disputes between rationalism and constructivism (Fearon and Wendt 2002). We take a pragmatic approach that combines the insights of PA and organizational theory to illuminate different aspects of the role of culture in processes of organizational change. Taken together - rather than tested against one another - the models can better explain what we observe in the case of World Bank reform and potentially other instances of IO reform. 


\section{Reforming the World Bank}

The catalyst for the Strategic Compact reform initiative in 1996 was a series of scathing internal reports revealing both the Bank's neglect of environmental and social assessments as well as the dramatically declining performance in the effectiveness and sustainability of the Bank's overall lending portfolio. ${ }^{13}$ Most prominent of all these critiques was the explicit condemnation of the Bank's bureaucratic culture by the 1992 Wapenhans Report, wherein the culture was characterized by a pervasive 'disbursement imperative', 'approval culture', neglect of project evaluation and feedback, and an overly centralized, hierarchical administration in Washington, DC that oriented staff towards internal bureaucratic manoeuvring rather than the results of projects on the ground (Portfolio Management Task Force 1992: 30-31). ${ }^{14}$ This culture, originating from McNamara's tenure at the Bank in the 1970s, reflected a development philosophy defined by neoclassical economic orthodoxy and a strict adherence in theory (if not in practice) to apolitical assistance. This culture allegedly encouraged staff to be secretive and to push large project loans based on a common blueprint that was amenable to the rapid disbursement of funds. At the same time, this culture did not reward careful follow-ups during the project implementation phase and thus often failed to meet the most fundamental needs of borrower countries.

In 1996, Wolfensohn and his newly constituted senior management presented a USD 250 million, 4-year reorganization proposal to the Bank's Executive Board of Directors. The first component of the Compact was designed to improve the Bank's relationship with developing-country borrowers by reallocating resources towards the 'front line' of operations and by moving away from 'blueprint' lending to more country-specific projects. Wolfensohn sought to revamp the Bank's image from an 'inwardlooking' to a 'results-oriented and country-focused' institution through the decentralization of management and staff from the Washington, DC headquarters to the field offices around the world. Critically, this also entailed shifting control of the internal administrative budget towards the Bank's country directors, a third of whom were also moved from Washington, DC to mission offices. Country directors could then contract (at hourly rates) for the services of staff specialists through detailed work programme agreements that were intended to streamline project management, cut overhead costs and better match staff skills with specific programme needs.

At the same time, Wolfensohn and his senior managers sought to redefine the Bank's basic mission and identity - both under attack by member states and NGOs alike - by reframing its traditional approach to development and proffering its role as a global 'Knowledge Bank'. The neo-liberal economic paradigm that infused the Bank's approach to development would be amended 
with greater attention to new or previously neglected issues such as social, environmental, and 'governance' projects. To encourage staff to pay serious attention to these new ideas, the Compact promised an increase in the number of staff who had expertise in these fields - that meant more sociologists, management consultants, anthropologists, ecologists, and even political scientists. The positions of these new experts would be institutionalized within four 'thematic networks' designed to facilitate links between research and operations and would help to enhance the Bank's reputation as the global leader in development ideas and information. ${ }^{15}$

The organizational pillar of the Compact was an ambitious architectural reform under the new 'matrix management system' intended to improve the management of the Bank's lending portfolio. The key purpose of this massive - and incredibly complex — bureaucratic reorganization was to disrupt the underlying organizational culture and in its place create new structures of authority and incentives that would realign staff expectations and behaviour with the desired image of the 'new' transparent, responsive, and efficient Bank.

\section{Evaluating the Compact's results}

How much did Wolfensohn's attempt to shake up the structure and culture of the Bank lead to any real change? To answer this question, we analyse staff behaviour in 1996, before the Compact was implemented, and then again in 2001, after the implementation period. We primarily utilize the Bank's own assessment of staff behaviour as described in internal and publicly available documents from the Compact preparation period (1996-1997) and the postCompact internal assessments. We recognize that our reliance on internally produced post hoc evaluations of the Compact and other performance data (such as the annual operation evaluations of the Operations Evaluation Department and the Quality Assurance Group) may raise doubt among some close Bank observers who perceive these sources as being prone to emphasizing positive findings and toning down negative results. However, close readings of these reports (and in particular their annexes which were not available publicly) reveal remarkably frank language, and our awareness of possible biases leads us to take particular note of where these reports reveal evidence of Bank staffs' behaviour and operational practices failing to meet the Compact expectations. Our research further delved into relevant assessments by sources outside the Bank - particularly NGOs that are (due to their watchdog missions) more likely to hone in on those areas where a desired change did not occur. Finally, we also conducted 30 interviews with Bank staff members to compare the official Bank assessment with the informal internal perceptions. Thus, we did our best (albeit, given the limited data in some areas) ${ }^{16}$ to use a balance of 
Table 1 Summary of the compact categories and priority areas

\begin{tabular}{ll}
\hline Category & Priority areas \\
\hline I. Mission & 1. Prominence of the social/environmental agenda \\
II. Organizational structure & 2. The matrix management system and thematic networks \\
& 3. Decentralization \\
III. Project (task) management & 4. Increasing project cycle efficiencies \\
\hline
\end{tabular}

sources and to measure organizational change qualitatively - and quantitatively where possible and appropriate - on the basis of observed and perceived 'gaps' between Wolfensohn's stated goals in 1996 and staff behaviour in 2001, at the close of the reform period.

Our observations cover four 'priority areas' of the Compact, which we subsequently divide into three categories. First, we examine one key issue that concerns the Bank's core mission: dramatically raising the prominence of the social/environmental agenda within its loan portfolio and in Bank-sponsored research. Second, we look at the initiatives to alter the Bank's organizational structure via the creation of a 'matrix management' system and the new thematic networks, as well as the decentralization of staff to the field. Third, we examine initiatives to improve project management, including efforts to streamline project cycles while simultaneously increasing portfolio permanence across numerous indicators (Table 1).

In all three categories, we find that our 'synthetic' model better explains the process and outcomes of reform than the stand-alone hypotheses offered by the PA and constructivist models. In particular, the degree of observability of staff compliance with new rules and adjacency to pre-existing cultural traits matters greatly: when both are present, significant change does occur. Where either is absent, the results are mixed. Where both are absent, change is slow or nonexistent. Surprisingly, on closely evaluating the results of the Compact, we uncover instances where different objectives of the Compact may have contradicted or undermined each other, created mixed signals for staff by proposing conflicting operational norms, and in some cases, unintentionally reinforced cultural elements that the Compact was designed to eradicate (Table 2).

\section{Environmental and social agendas}

In the past two decades, critics had sharply attacked the Bank for its indifference to the social and environmental impact of its projects. This is especially true with respect to the lack of consideration to the impact on local indigenous populations and the surrounding natural environment in the 
Table 2 Summary of qualitative findings

\begin{tabular}{lllll}
\hline Compact category & Measurability & Norm adjacency & Cultural change & Amount of reform \\
\hline Environmental/social & High & Low & Medium & Medium \\
Decentralization & High & High & High & High \\
Matrix and networks & Medium & Low & Low & Low \\
Project cycle efficiency & High & Medium & Medium & Medium \\
\hline
\end{tabular}

planning of large infrastructure projects. While a significant reassessment of these practices had been occurring for some time (Rich 1994; Wade 1997; Fox and Brown 1998), the Compact directly addressed these issues anew.

By 1996, the Bank had undergone a major reassessment of its environmental policy in project design and implementation requiring all projects to be categorized according to their potential ecological and social impacts (Wade 1997; Udall 1998). Projects determined to be environmentally risky were required to include an environmental assessment prior to loan approval, increased monitoring for environmental impacts during implementation and, if needed, mainstreamed funds for environmental remediation. But criticism persisted that these adjustments (or at least staff and borrower government adherence to these policies) fell short of adequately safeguarding the environment (Fox and Brown 1998). Moreover, stand-alone environmental lending had reached an apex in 1994 for overall lending dollars, declining in 1995 and 1996. The Compact thus called for a heightened commitment to expanding and implementing the environmental lending and safeguards.

The social agenda was less well developed in 1996. In conjunction with the Compact, a cross-disciplinary social development task force met in 1996 and began unifying goals, concluding that greater attention needed to be paid to 'incorporating the social dimensions of development into the Bank's work' (World Bank 1997a; cf. World Bank 1997b). This largely included deepening programmes in poverty alleviation (accomplished through investment in programmes for health and education broadly defined), gender, indigenous peoples, resettlement, local/civil society involvement, and social assessment. Social lending had been increasing steadily since 1980, but the Compact called for a sharp increase in that commitment and staff attention to social considerations in project design and implementation.

As a result of the Compact, the Bank hired more social and environmental staff. At the headquarters, 86 new staff members were hired for social development (World Bank 2001a, Annex 2: 4), 45 upper level staff were hired by the Environmentally/Socially Sustainable Development (ESSD) network, as were 50 new staff in the Human Development (HD) network (World Bank 2001a, Annex 6: 4). At the country offices, another 42 new ESSD staff were 
hired in addition to 23 new HD staff members (Ibid: 6). Internal assessments assert this is a positive sign of change in the direction of social and environmental mainstreaming (although the limitations of the data lead us to question this claim - see endnote 16).

Since the Compact's implementation, progress in 'mainstreaming' the social and environmental category has been mixed. On the one hand, we find that where tangible incentives could be designed, and staff performance evaluations linked to them, staff behaviour and policy outcomes moved toward the Compact goals. For example, if we are to count the total number of projects by sector, we find that the environmental and social sectors hold steady or increase - sometimes dramatically - as a share of overall Bank activity where other, more traditional sectors, particularly energy, decline. This seems to us to be strong evidence that, where performance was measurable (as expected by the PA hypothesis), a movement toward the goals of the Strategic Compact occurred.

In Figure 3, we include Bank-managed Global Environment Facility (GEF) projects, which have absorbed a disproportionate amount of staff time and attention when compared to World Bank stand-alone environmental projects. This change in project management reflects a considerable shift of staff energy to social and environmental concerns. To the degree that energy, urban

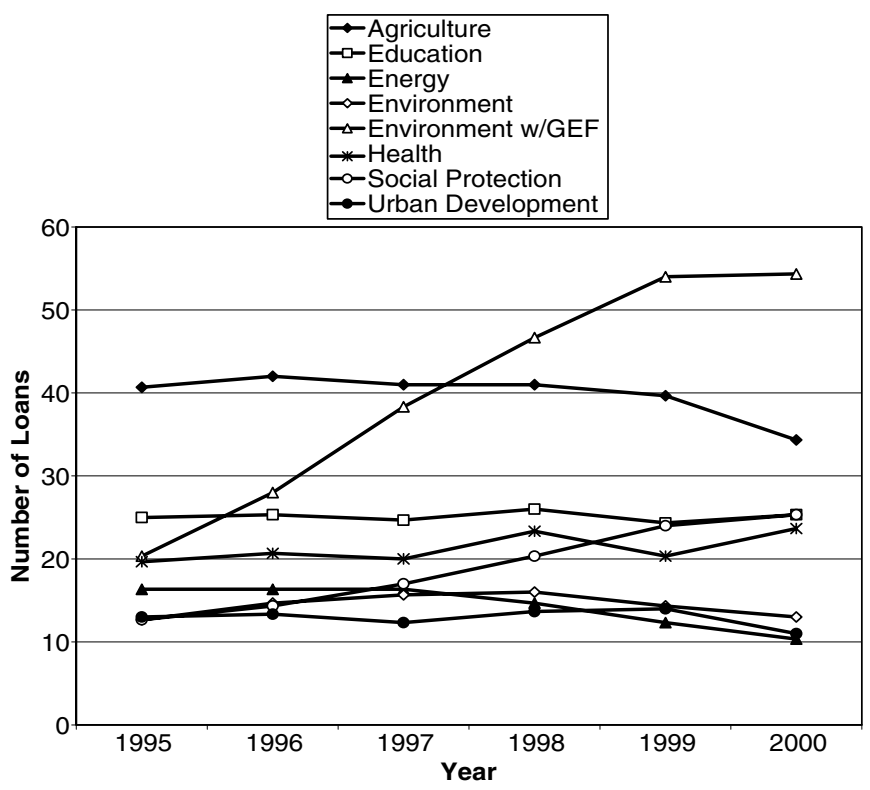

Figure 3 Number of World Bank loans in selected categories, 1995-2000 (3-year rolling average). 
development and agricultural loans are considered problematic for environmental and social sustainability, this trend could also be interpreted as movement towards the Compact's goals. Particularly in the Social Protection Sector and the Environment (when Bank-managed GEF projects are included), these trends seem to represent real progress towards the Compact's goals and thus a shrinking of the gap between the principal's preferences and the outcomes implemented by Bank staff. ${ }^{17}$

The Bank's qualitative evaluations echo our own findings. The 2001 internal assessment notes that - considering nine individual dimensions - quality improved for all Bank operations in all dimensions, most substantially in the areas of poverty alleviation and social development. Of the nine evaluated, the sole outlier was the environment dimension. But the report emphasized that this result occurred not because the environmental quality of the operations had deteriorated, but because the assessment standards had become more rigorous, requiring both stricter and earlier assessments, and necessitating the involvement of an environment specialist in every project (World Bank 2001a, Annex 2: 3). Both the reorientation of the project portfolio toward social and environmental sectors and the quality assessment on these dimensions are measurable - and quantifiable - aspects of the Compact. So, based on the logic of the PA hypothesis, we expect a significant shrinking of the gap. This is indeed what we observe whether we look at broad, quantifiable measures of lending or at the internal evaluation reports.

Alternatively, constructivist logic suggests we should see little to no change in the size of the gap, as environmental and social concerns are not coincident with the Bank's pre-existing culture. In an organization defined by economic orthodoxy and moving large amounts of money as quickly as possible, we would expect staff members to ignore such 'peripheral' issues, especially when they slow down the loan approval and disbursement process and require enormous staff time and resources.

Indeed, there is some evidence of cultural inertia that casts doubt on the extent of the behavioural change we would predict through the PA hypothesis alone. Changing core values and beliefs about the importance of environmental and social policy outcomes has been slow, which produced mixed results in terms of the quality of environmental and social assessments in project lending. Numerous staff interviews, internal memos and external NGO reports cast doubt on the extent to which these agendas have been internalized in ways that compel staff to take these issues seriously (Rich 2002; Winters 2002).

In part, this shortcoming is due to a conflict with another part of the Compact programme. In a recent report by the Bank's Operations Evaluation Department (OED), the authors make special note of the Environmental Department's loss of budget control to Country Directors as part of the decentralization initiative and the introduction of a new internal market system 
for hiring consultants to carry out environmental and social impact assessments. While task managers are required under the formal safeguard policies to include an environmental specialist in various stages of project planning and implementation, these managers quickly discover which specialists will raise serious questions and which ones will be more lenient. Given the continuing career incentive to move money and to please borrower governments seeking unhindered loan approval, strategic managers often 'hire' compliant specialists who will not carry out lengthy and expensive environmental assessments that may hold up or add to the total costs of project preparation or supervision (Operations Evaluation Department 2001b; Rich 2002: 40). ${ }^{18}$ Note that specialists face similar perverse incentives to approve projects rather than raise tough environmental questions. After all, if the career rewards to a specialist are really based on the demand for their services in the internal market, compliant specialists will be in greater demand than strict ones. Here, as suggested by constructivist logic, actual behavioural changes (and especially project outcomes on the ground) fall short of the change predicted by the strict PA hypothesis. Even with good information about agent behaviour and outcomes, principals do not fully realize their goals because of a strong conflict with existing cultural norms (the disbursement imperative and approval culture). These normative constraints are reinforced by the new incentives of the internal market.

Like its PA alternative, the stand-alone constructivist hypothesis fails to account for the extent of behavioural and normative change that we observe on the environmental and social agendas. Several interview subjects report that interactions with 'non-traditional' (read: non-economist) staff have increased, and task managers and other front-line staff are much more attuned to social and environmental issues even though they often conflict with the approval culture and disbursement imperative. While many task managers bemoan the incorporation of safeguards into projects, many also agree that such safeguards are necessary and some even suggest that more safeguards are needed. ${ }^{19}$ Interviewees characterize this change as shallow but taking greater hold over time.

We expect, and anecdotal interview evidence indicates, that requiring task managers to include social or environmental experts in their team will induce some dialogue and reflection on the Bank's core mission, which is the first stage in a normative shift (Schein 1992). Combined with the increased number of environmental and social staff members, culture is likely to shift under these conditions, albeit slowly. Because staff members have only partially internalized these new norms and new thinking about the nature of development, behavioural patterns have shifted less dramatically than a purely incentive-based model might predict, yet still more than a stand-alone cultural model would expect. 


\section{Decentralization}

The dramatic administrative restructuring of the Compact was designed to illicit behavioural and even cultural change by altering the way in which staff interacted with management, other staff members, and especially borrowercountry governments. This reorganization included a massive relocation of nearly one-third of all staff to field offices and the devolution of authority (including budget authority) to the country directors (many now in the field), who had previously been beholden to Washington for the approval of nearly all operational decisions. With the Compact, country directors effectively became 'princes' in local financial fiefdoms, exercising much greater authority at various stages of the project cycle - especially after loan approval. ${ }^{20}$ Before 1998, roughly 1,900 members of the Bank staff were located outside Washington, DC. By 2001 that number had increased by 33 per cent to more than 2,469 (Figure 4).

Moreover, these new staff members in the country offices were increasingly drawn from local populations, where they reported they had attained increasing authority to make substantive operational decisions (World Bank 2001a: 29-30) in areas such as 'project supervision, procurement, financial management, and disbursement' (World Bank 1997b: 29, 2001a: 29-30). Our interviews with Bank staff in Tanzania in 2003, Chad in 2004, and Washington, DC in 2003 and 2004 confirm a shift in the planned direction. Moreover, while only three country directors were located outside Washington in 1997, by 2001, that number had grown to 29. These country directors now based in the field made 70 per cent of the loans for the 2000 fiscal year (World Bank 2001b).

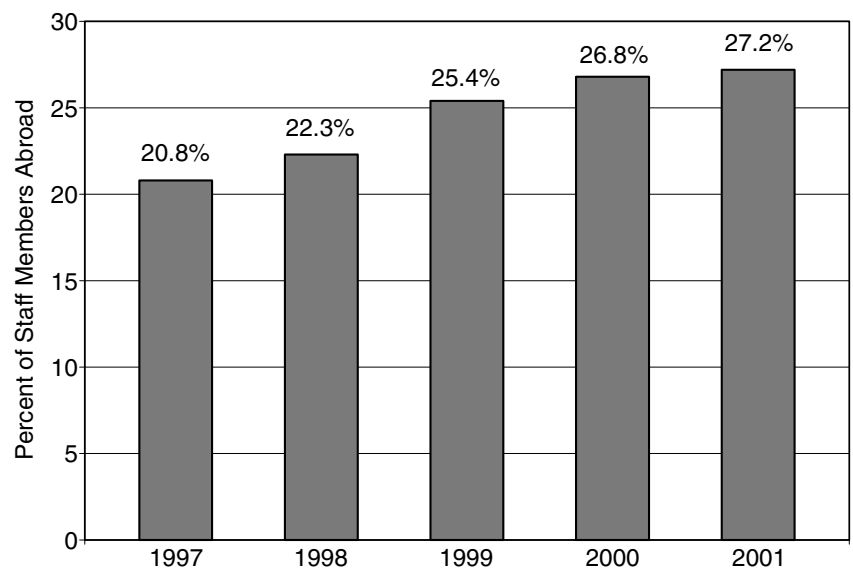

Figure 4 Decentralization of World Bank staff source: World Bank (2001a, b: 36). 
This decentralization, combined with altered hiring priorities, resulted in a 33 per cent turnover of Bank staff during the Compact's implementation period - an unprecedented figure at an organization where the usual change in staff would be closer to 3-5 per cent for a typical 4-year cycle. ${ }^{21}$ Many of the longserving traditional staff took early retirement rather than leave Washington, DC and resettle in a regional office. Such massive staff turnover obviously allows the President and senior management to select new employees that possess the skill sets and normative commitments that more closely reflect management's preferences.

Recall that Wolfensohn's purpose behind decentralizing Bank operations was to make the Bank more responsive to recipient-country clients. Data from internal Bank reports tell us little about whether all this re-shuffling had any of the intended effects. However, in May 2003 an independent survey of 2,600 opinion leaders in 35 developing countries provided dramatic evidence indicating that the decentralization reforms had precisely the effects intended by Wolfensohn. In all six regions of the developing world, respondents overwhelmingly indicated that the Bank had become more responsive to the demands of borrower governments (although not necessarily the civil society groups in those countries). Aggregated answers indicate that 59 per cent believed the Bank had become more responsive over the past few years, while only 18 per cent thought the Bank was less responsive. ${ }^{22}$ Based on this survey data and qualitative evidence from other researchers (Mallaby 2004: Chapter 8), it appears that decentralization had its intended effect. Because these Compact goals were both tangible and measurable, the PA model predicts dramatic and sustained changes to the structure of the Bank. Changes in organizational outcomes were indeed dramatic, suggesting that the tremors of principal demands can rock the foundations of even the most 'stable' IOs if the conditions are right. The conditions highlighted by our synthetic model focus attention on the fit between the proposed reforms and the pre-existing culture. Unlike the outcome in the environment/social case discussed above, in the case of decentralization, the fit was near perfect since a focus on borrower preferences enabled project approvals and rapid disbursement.

Direct evidence regarding changes in traditional attitudes about field assignments and the efficacy of borrower development ideas is mixed. We were surprised to find that although 'old hands' at Bank headquarters in Washington, DC have yet to start coveting field assignments, six of seven interviewees in the same field office in Tanzania had worked in Washington and reported a preference for the field! A seventh had never worked at headquarters and, although he expressed interest in a short-term assignment there, he planned to return to the field. ${ }^{23}$

However, other Bank employees assigned to field offices express feelings of 'disconnection' from the Washington office which 'leave them out of the loop' 
on new assignments or promotions. But this disconnection, paradoxically, also pleases many of these same personnel in the field. It allows them to work more closely with client countries, an explicit directive under the Compact. Of course, mission staff are not completely autonomous even after significant decentralization. According to a field officer in Moscow, the responsibilities of the mission office are regarded by borrowers and Bank staff alike as another layer of red tape, with all decisions of consequence relayed to Washington. ${ }^{24}$ Such perceptions suggest limits to the progress made in engendering a 'listening culture' in Bank operations. 'While staff are encouraged to listen to their clients in the field, they frequently find resistance in Washington to tailoring Bank approaches to heed what they have heard. And still to an apparently excessive degree, they find themselves pressing their clients to use Bank guidelines, policies, systems, and ways of planning' (World Bank 2001a, Annex 8: 14).

Nevertheless, in terms of cultural change, the decentralization reforms resulted in significant movement towards Wolfensohn's goals compared to other Compact priority areas. This is likely because the norms required to achieve the improved country focus were largely in place in what the Wapenhans Report called the 'approval culture' and the 'disbursement imperative'. The norms accompanying decentralization were thus adjacent to norms prevailing in 1996. Attuning decision-making to the particular interests and demands of the Bank's borrower governments involved significant readjustments to the Bank's architecture, yet could be accommodated within the existing informal ideologies, norms, and routines. Not surprisingly, borrowers also want large loans with quicker disbursement. In this respect, task managers and borrower governments shared a strong interest - one that the Compact had given them a green light to pursue under the cover of 'responsiveness to client concerns'. The accompanying aim of shifting from abstract, blueprint development knowledge and a Washington-centric focus to a tailored, client-centric approach proved slightly more difficult, yet not completely resistant to re-organizational efforts due to some inherent synergy with existing bureaucratic norms.

Because cultural change and material incentives reinforced one another in this Compact area, we expected to see a significant reduction in the size of gaps between principal demands and staff behaviour at the end of the Compact period. Our expectations were met. The evidence suggests that the cultural change resulting from the push to decentralize likely reinforced and accelerated the reduction in gap size.

\section{Matrix Management and Thematic Networks}

The Compact's massive overhaul of managerial lines of authority and introduction of thematic networks of expertise was intended to promote the 
cross-fertilization of new ideas with prevailing practices, break down existing organizational fiefdoms, and diffuse new operational norms and patterns of interaction. Specifically, the new matrix management system introduced an internal, competitive contracting system based on work programme agreements. Under the system, country directors ('CDs') possess increased control over a majority portion of the Bank's administrative budget. The CDs use the budget to contract with the Bank's new centres of expertise (the thematic networks) to find those staff members with the most appropriate skills to fulfil country plans, assemble project teams, and design and appraise specific loan projects. ${ }^{25}$ Aligned with the goal of developing greater expertise in new agenda areas and tailoring operations to client demands, the matrix system was intended to eliminate the supply-driven work and organizational patronage networks that drove the old approval culture.

This reorganization differed dramatically from the hierarchical and centralized structure of the Bank's past, which largely persisted until 1996. Previously, the regional vice presidents - all of whom worked above the CDs - exercised the bulk of operational authority. Over time, vice presidencies were established to cover functional issue areas (such as the environment), but they exercised no managerial authority over front-line staff and thus had a marginal impact on operational decisions. In part, the centralized/hierarchical structure fed criticisms of the Bank that the incentive structure for the key personnel in areas of environmental and social lending, for example, had not changed despite the Bank's prior reforms (Fox and Brown 1998).

The Matrix and Networks system was intended to counter this hierarchical approval culture. Making staff members responsible to both a technical/ thematic manager and a country manager, with each manager contributing evaluation memos to the staff member's file, would likely motivate staff members to take seriously the concerns of the network, in addition to the country office. Individual task managers now had stronger incentives to vet proposals with multiple units within the Bank - both those in their region and those in their network.

In theory, the material incentives motivating Matrix Management and Networks should be relatively easy to implement and the related behaviour simple to measure. Yet, ambiguity in implementation of the system and continuing confusion over formal versus informal lines of authority means that evaluating the effect of the matrix system on changing staff behaviour is difficult. Thus, we categorize staff behaviour under Matrix Management as less measurable than decentralization or task management. Still, the material incentive aspects of the system - particularly in the concrete career implications for staff members - ought to compel some change of agent behaviour towards the principal's goals. 
However, the Matrix also had consequences that Wolfensohn's team did not intend; it created 'stress, job insecurity, and poor morale as staff competed with each other for work' under the new work programme agreements and internal market system. Instead of promoting co-operation between operational units and thematic networks of experts, it 'resulted in protectionism with budgetary disincentives to using people from other units,' which directly counteracted the intended outcome of greater cross-organizational collaboration between research divisions, sector networks and operational units (World Bank 2001a: 42). One assessment concludes that the internal market inadvertently obstructed knowledge sharing despite the fact that this was a central goal of the new thematic networks, as 'budget downsizing and job insecurity create incentives for staff to hold onto knowledge as a form of power' (World Bank 2001a, Annex 3: 11).

In our interviews, few staff - aside from those explicitly involved in the design of the system itself — had favourable things to say about Matrix Management. Yet, the same interview subjects also acknowledged that the system has altered the Bank, and their own behaviour, significantly. While they complained of ambiguities and cross-purposes, they also noted that they were now much more aware of the broader purposes of the Bank and the multidimensional character of development.

Our alternative models generate broadly similar predictions for this area. Since behaviour under the new management system was relatively difficult to measure, we expect less change here than in other areas of the Compact. Likewise, since the norms embedded in the matrix system contrast strongly with the prevailing hierarchical interaction patterns, we expect larger gaps here than in other areas. Nevertheless, since this was the area of the Compact that most directly targeted the organizational culture explicitly given that it aimed at dramatically altering the patterns of interaction within the organization, this was also the area where even a modest change in culture could be expected to magnify the impact on staff behaviour. As noted above, the Matrix Management System is among the most important components of the Compact as it removed the hierarchy that obstructed the kind of widespread informal interactions that catalyze cultural change. While the resulting cultural changes have been modest, the eventual effects may grow over time. ${ }^{26}$

\section{Increasing Project Cycle Efficiencies}

The 1992 Wapenhans Report and subsequent internal evaluations clearly indicated that the performance of Bank loans was declining, inciting many critiques of wasted aid money. The report found that the number of projects judged unsatisfactory upon completion by the Bank's own evaluation 
standards had increased from 15 per cent in 1981 to 30.5 per cent in 1989 and to 37.5 per cent in 1991. Within the total portfolio, the share of projects with major problems had increased to 20 per cent in 1991 and cancellations of lending programmes had reached 50 per cent by 1989-1991. Moreover, the 1992 report revealed a very low level of borrowers' compliance with the legal covenants attached to loans, with only 22 per cent of all loan conditions being fulfilled in 1991 (Portfolio Management Task Force 1992: 9).

This report was remarkable for its specific condemnation of the Bank's internal culture as the key cause of declining project performance - something noted at length in the pre-Compact assessments. For the first time, the internal evaluations identified the perverse incentives reinforcing the aforementioned 'approval culture' and 'disbursement imperative' in which staff pushed new loans and spent enormous amounts of time and energy steering projects through multiple layers of senior management and the Executive Board. Staff correctly perceived that promotions were distributed on the basis of lending quantity, and thus they had the incentive to seek out fundable projects even in the absence of client initiative, interest or the successful implementation of prior projects. Project appraisals were conducted quickly, with little or no regard for the Bank's own environmental and social safeguard policies, and thus tended to be overoptimistic about the projects' chances for success in order to get the borrower government on board and attain internal approval. The zeal to lend overshadowed concerns about planning, implementation, and risk assessment.

Predictably, project management after loan approval often suffered as task managers and team members frequently abandoned projects soon after they were started. ${ }^{27}$ In order to move up in the organization you had to 'move on'. This led to considerable staff turnover and discontinuity in the management of individual projects and severely hindered ongoing supervision (something highly under-resourced in terms of staff time and money), including the monitoring of borrower government compliance and the realistic assessments of project risks and sustainability.

Wolfensohn and the senior management specifically targeted improvement in portfolio management as a key component of the Compact. Many of the problems outlined above were addressed through the internal market system, the Matrix Management system, and through new rules regarding the 'streamlining' of project approval. ${ }^{28}$ Overall, the goal was to create top-down pressures on managers and project staff to produce loan performance results that would show improvements in project quality at entry, the likelihood of sustainability, and a much greater potential for institutional development impact (Operations Evaluation Department 2001a, 2002; Quality Assurance Group 2001: 12). A parallel imperative was to replace the approval culture with a 'results-oriented culture' by reducing the number of projects in the Bank's 
overall portfolio that are 'at risk' of implementation failures or a low development impact.

Here, the attempts to re-engineer incentives and the culture surrounding project management are intricately intertwined. Overall portfolio performance ratings, as indicated in Appendix 1, did improve quite dramatically according to the Bank's own measurements. Indeed, the time from project conception to Board approval also decreased substantially, in part by reducing the time from project appraisal to negotiations (Figure 5).

Yet, many recent evaluations note that, where new rules clashed with previous norms and practices, the results have been mixed and the numbers may misrepresent the degree of actual change in project management. In general, the goal of streamlining project appraisal may be undermining the second goal of improving project design and management. As one senior staff member argued, the push to get projects appraised and approved more quickly to placate client demands for cutting red tape has reinforced rather than countered the approval culture of the Bank. ${ }^{29}$ As a result, he argued, the quality of projects going forward to the Board is actually worse and staff members are left cleaning up the mess during project implementation (with the subsequent problem of lengthening the project implementation period even as project approval time is shortened). This is not entirely surprising, as speeding

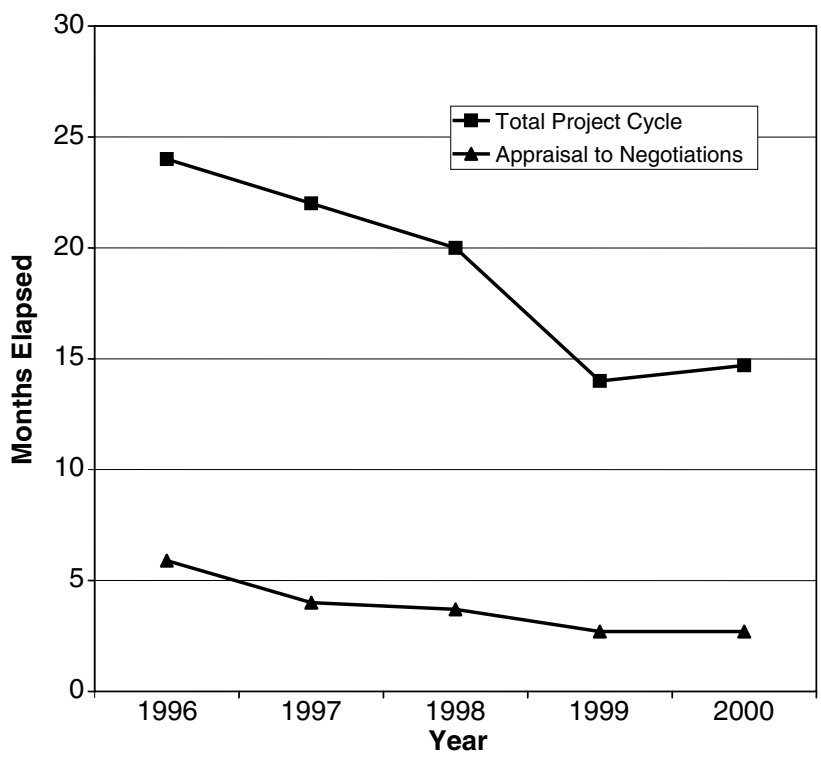

Figure 5 Streamlining the project cycle source: World Bank (2001b: 10). 
up the approval process is something that is simultaneously compatible with the existing culture as well as easily measurable and therefore coveted as an area that can be heralded as a success for the Compact programme.

Specifically, one primary goal was to introduce formal incentives and norms that would compel staff to focus more on carefully monitoring projects throughout design, appraisal, implementation and outcome. One specific goal was to ensure that any projects 'at risk' were either cancelled or fixed to ensure that projects actually produced the desired development impact. Indeed, the evaluation statistics do indicate that the number of at-risk projects has declined since the initiation of the Compact. However, the quantitative findings indicate greater behavioural change than the qualitative findings. For example, the Annual Report of the Quality Assurance Group (QAG) in 2001 warns that the top-down pressure may be compelling task managers to under-report risks. Projects are not given an 'at-risk' designation until the project manager places three or more warning 'flags' in the project files. As a result, managers will often avoid giving a third flag or apply 'golden flags' which over-ride existing risk designations. QAG estimates that even if only one-quarter of the projects holding two risk flags were given a third one, the overall percentage of projects at risk in the total loan portfolio would jump from the current 12 to 16 per cent, thereby exceeding the Compact's target. The implication in the report is that the internal pressures to produce desirable ratings and the cultural norms favouring excessive optimism in appraisal and supervision exercises have prevented the kind of candid evaluation needed to prevent a rise in the number of projects at risk as the Bank's overall portfolio moves into considerably more complex and demanding areas of lending.

Persistent, chronic weaknesses in the formal mechanisms and incentives governing monitoring and evaluation are further impeding the Bank's shift towards the desired results-oriented culture. Despite the recommendations of the Wapenhans Report and the articulated goals of the Compact, staff members still tend to focus primarily on the project inputs rather than the process of implementation and attention to issues of sustainability, perhaps because designing a contract that measures such qualities is quite difficult. Achieving success in this Compact goal will likely require a cultural change that we have not yet observed. Current statistics on supervision evaluations support this assertion, showing a small improvement in some areas but, as implied above, continuous problems in managing ongoing projects that are considered at risk. Thirty per cent of sampled projects in the QAGs 2001 report scored less than satisfactory on the monitoring and evaluation criteria (Quality Assurance Group 2001: 24).

Moreover, attention to the dramatic improvement in the percentage of exiting projects showing satisfactory or better outcomes is dampened by the modest and even dismal statistics on the current percentage of projects 
promising likely or better sustainability after completion (70 per cent) or substantial or better institutional development impact (only 56 per cent) (Operations Evaluation Department 2001a: Table 7). ${ }^{30}$ These numbers are even lower in the key sectors and regions that have been specifically targeted for reform. For example, the likelihood of the sustainability of projects associated with environmentally and socially sustainable development averages out at only 53 per cent over 2000-2001, with an institutional development impact rating of just 43 per cent.

Beyond the confusion in the extent of the Bank's versus the borrower's role in monitoring and ensuring compliance during implementation, managers and staff still remain unconvinced that good quality supervision is recognized or rewarded in the same way as lending work. As a result, despite increases in resources devoted to supervision, the focus is still on upstream rather than downstream project management as under the pre-existing approval culture, and supervision remains the first item to be cut in any of the regional budgets (Bank Information Center 2001).

\section{Conclusion}

Changing the culture of any organization is a lengthy and complex process. The change process itself is influenced by the culture in place. If the latter is strong - when shared beliefs, values, and norms consistently drive behaviour - the change process is even more difficult. Such is the current situation in the Bank (World Bank 1987: 16).

It certainly comes as no surprise to observers of the World Bank that reforming this massive international bureaucracy is an arduous process, prone to unexpected setbacks and undesired outcomes from the perspective of the Bank President. Further, the impediments to reform are not limited to dissent among the Bank's member governments (Nielson and Tierney 2003) or active resistance from obstructionist bureaucrats. Rather, as the lines quoted above from a 1987 evaluation of reform suggest, one key impediment (or enabler) of reform is organizational culture.

As our case study of the Compact illustrates, culture can either constrain and thwart the efforts of a reform-minded principal (as in the case of the matrix system) or it can enhance the prospects for reform and help principals to realize their policy objectives (as in the case of decentralization and reforming the project cycle). While we began with a relatively stark PA model that focuses on formal authority, the preferences of actors, and information asymmetries, we found that this model could not explain the range of variation seen in reform outcomes at the Bank without incorporating the insights of 
constructivist organizational theory. By combining the insights of both approaches as compliments (Fearon and Wendt 2002), we can improve our perspective on two issues that have, thus far, been weakly addressed in the IO scholarship: the relationship between the culture and behaviour of IOs and the dynamics of IO reform.

Indeed, recent articles on IOs in this journal and other prominent international relations sources have increasingly focused on organizational culture as a critical variable in understanding patterns of norm creation and diffusion (Park 2005), theory and policy shift in areas such as international finance and capital controls (Leiteritz 2005), and sources of organizational 'pathologies' (Barnett and Finnemore 2004). Nonetheless, culture remains a tricky concept - one that is difficult to define, measure, observe, and test (Hamlet 2004). We certainly have no allusions that our synthetic model and the case of the World Bank resolve these issues, but we do believe that it represents a viable research agenda that can be greatly strengthened through modification and application to other IOs. At the least, we are confident that our pragmatic synthetic approach is not only progressive in terms of International Relations (IR) theory but it can potentially be useful for informing real policy debate about how we might construct, implement, and evaluate IO reform.

Indeed, our imperative of better understanding World Bank reform has real merit in world politics. At no time since the end of World War II have scholars, policy-makers and citizens needed to understand the causes and consequences of organizational reform at the international level more than we do today. Beyond the World Bank, the International Monetary Fund (IMF) and other international financial institutions face demands for increased transparency and accountability that mirror many of the reforms enacted at the Bank. The European Union (EU) member governments, and in many cases its citizens, are currently debating organizational and constitutional reform on a grand scale. The United Nations (UN) Secretary General has commissioned a study to reform the membership and voting rules of the Security Council for the first time in over 50 years. Unsatisfied with this effort, some member governments of the UN have pre-empted this process and launched reform proposals (or demands) of their own. As IOs across a range of issue areas become more consequential and demands for reform intensify, there is a clear need for theoretically informed empirical research on this topic. While we have only examined a single IO in this article, the plausibility of our model and our empirical findings encourage us to generalize our synthetic approach to other cases and test similar claims in other organizational settings. We are hopeful that our attempt to bridge the rationalist-constructivist divide within the context of actual empirical research will dampen the enthusiasm for paradigm wars among IR theorists and enhance our understanding of IO behaviour and change. 


\section{Notes}

1 This article was originally presented at an ISA-funded workshop in Budapest, Hungary in 2003 entitled Theoretical Synthesis in the Study of International Organizations. For comments on various drafts, we thank Michael Barnett, David Dessler, Marty Finnemore, Darren Hawkins, Tamar Gutner, Ralf Leiteritz, James Long, Brad Parks, Robert O'Brien, Jess Sloan, Duncan Snidal, Alex Thompson, and Stephen Watts. Generous financial support for this research was provided by the Programme on the Theory and Practice of International Relations at William and Mary, The National Science Foundation (Grant SES-\#0454384), the University of Kansas Policy Research Institute and General Faculty Research Fund, and Brigham Young University. We would especially like to thank the editors of the JIRD and the two anonymous readers who offered some of the most thoughtful suggestions that we have ever seen in the review process. James Long and Chris O'Keefe provided research assistance. Any remaining shortcomings in this article remain our responsibility.

2 Interviews with Bank staff members, July 2005, Washington, DC.

3 Notable reorganization attempts include those by Bank presidents McNamara (1972), Conable (1987), and Preston (1992-1993).

4 For related discussions about the benefits of theoretical synthesis, see Snidal (2002), and Lake (2002). However, few scholars have offered explicit and generalizable blueprints for actual synthetic models that could be applied to empirical cases. For exceptions, see Jupille et al. (2003) and Tierney and Weaver (2005). While our approach is distinctly positivist, in practice it shares many features of the Haas and Haas (2002) vision of a 'pragmatic constructivist approach' that highlights the benefits of synthesis for empirical analysis while side-stepping some of the most challenging ontological issues.

5 We purposely take a narrow constructivist approach here that analyses the effects of organizational culture on staff behaviour. Many other works take a broader constructivist perspective, addressing both how the world is understood by Bank staff through the "lens of organizational culture' and, in reverse, how the world understands 'development' as a product of the theories, policies, and practices embedded within a distinct Bank culture. See, for example, recent works by Bøås and McNeill (2004) and Goldman (2005).

6 For a recent discussion of the socialization effect of international institutions, see articles in a special edition of International Organization (Checkel 2005). For a nuanced discussion of the logic of appropriateness employed in constructivist theory, see Sending (2002).

7 This is similar to Jupille et al.'s (2003) model of sequencing or to Legro's (1996) 'cooperation two step.'

8 PA theory suggests other reasons for agent autonomy in addition to information asymmetries, such as heterogeneity of preferences among multiple principals, agenda control, and the credibility of principal threats and promises (Hawkins et al. 2006). We do not examine these variables here.

9 Momani (2005) discusses different types of organizational cultures. In her analysis of the IMF, she explains that the Fund's technocratic culture was particularly resistant to change. While we see important differences between the World Bank and the IMF's organizational culture, especially in terms of the professional diversity of the staff, tenure, and centralization, the Bank shares many of the technocratic imperatives that characterize the Fund. In our interviews with Bank staff, we recorded many beliefs and values that were similar to those reported by Momani at the Fund. Predictably, staff members who had been at the Bank the longest tended to reflect this technocratic culture the most strongly.

10 We limit ourselves here to discussing efforts at organizational change that are driven primarily by member states via Wolfensohn and his management team ('top-down'). At the same time, we recognize that there are other possible origins of change, both from non-principals outside the organizations (such as NGOs or private banks - Park 2005 and Gould 2006) and change 
entrepreneurs from the lower and middle rungs of the organization itself (Kardam 1993; Bebbington et al. 2004).

11 For arguments on the adaptive tendencies of IOs, see Tendler (1975), Crane and Finkle (1981), Kardam (1993), Finnemore (1996), Miller-Adams (1999), and Weaver (2005).

12 However, this could work in both directions. New staff could 'learn' lessons from pre-existing staff members. Some of our interview subjects hired in the past 5 years reported powerful informal incentives to conform to pre-existing norms and routines ... even when these routines 'directly contradict the stuff we memorized in those orientation sessions' (Interview with junior Bank official, Washington, DC, March 2002).

13 See, for example, the 1992 Morse Commission Report, the 1992 Portfolio Management Task Force Report, and the 1997 report by the Bank's Quality Assurance Group (1997). According to one member of the Bank's senior management who was familiar with the internal debate, Wolfenhsohn and the managing directors were also attempting to revitalize the organization, increase its administrative budget, and enhance information technology and human capital. The Bank could not do this, however, without convincing the Executive Board that it had something to offer in return (Interview with senior Bank official, May 2003).

14 For the sake of brevity, we do not provide a detailed explanation of the sources and evolution of this organizational culture. See, for example, Rich (1994) and Caufield (1996).

15 These four networks were situated between research, policy, and operational units and focus on the areas of Environmental and Socially Sustainable Development (ESSD), Human Development (HD), Finance and Private Sector Infrastructure (FPSI), and Poverty Reduction and Economic Management (PREM).

16 In a few areas of our research, we were simply unable to attain the data we sought to test some of our hypotheses. One example is the hypothesis about staffing changes as a catalyst for internal debate and 'ideological change' in the Bank. While the Compact assessment reports contain data on the total number of staff hired into key sectors in the Bank (environmental and social development, legal, economics, etc.), we were unable (despite repeated attempts) to obtain data that would tell us about the educational levels and background training of these new staff members. In other words, we know that a significant number of new staff were hired to work in the ESSD network, which might indicate a positive shift in mainstreaming these agendas, yet for all we know many of these new staff members are neoclassical economists rather than sociologists and ecologists (as suggested by a few interviews conducted in ESSD).

17 Measuring the number of projects is preferable to measuring the amount of money flowing to particular sectors if one is interested in a measure of organizational effort or staff time. This follows from the fact that large projects require less staff time per dollar spent. Environmental projects are smaller on average, but they still require preparation, oversight, and evaluation just like much larger infrastructure, agriculture, and structural adjustment projects (Nielson and Tierney 2005).

18 As one Bank veteran explains, "They can say what they want about the "new bank", but if you don't get your projects approved, everybody in this building knows it' (Interview with senior economist, July 2003, Washington, DC; and Bank official, May 2001, Washington, DC).

19 Interviews with Bank officials, May/July 2003, Washington, DC; June 2003, Dar es Salaam, Tanzania.

20 The 'princes' analogy was suggested by a senior economist at the Bank. Interview May 2003, Washington, DC. For numerous examples of the new authority of country directors, see Mallaby (2004).

21 Interview with senior Bank strategy official, May 2003.

22 Sixteen per cent reported no change in responsiveness and nine per cent gave no answer. For results broken down by region, see McIntosh et al. (2003: 68-69). 
23 Interviews with junior and senior officials, June-July 2003, Dar es Salaam, Tanzania.

24 Interview with Ludmilla Poznanskaya, September 1999, Moscow World Bank mission office.

25 Interview with Anil Sood and William Rex, February 2002, World Bank, Washington, DC.

26 Some economists interviewed for this project claimed that they did attend numerous training sessions, they were forced to interact with sociologists and biologists, and that they did have to send drafts of reports to these minority staff members. While many economists reported that 'these interactions have no impact on our thinking', they also reported that 'we did change the language of our report to accommodate their views and to ensure that we could communicate with a broader audience. This report is much more consumable than it would have been 5 or 10 years ago'. While this economist interpreted such an outcome as having 'no impact' on his thinking, a close reading of Wolfensohn's original goals suggests that such a change was part of the purpose of the Compact. Interview with senior economist, Washington, DC, May 2003.

27 The report specifically mentioned that no more than 40 per cent of the project supervision missions had the same staff for four missions (Portfolio Management Task Force 1992: 11).

28 The new 'streamlining procedures' expedited the Board approval process for any 'small loans that did not contain any significant environmental or social risk'. In these cases, the Board does not fully debate a loan, but instead reviews project documents prior to a meeting and simply votes yes or no.

29 Interview with senior Bank official, May 2003, Washington, DC.

30 The OED report also warns that these ratings are determined in part by the self-evaluations of task managers and project staff, implying that even here there may be excessive optimism.

\section{References}

Bank Information Center (2001) 'The Wolfensohn Revolution - Supervision and Incentives for Ensuring Results', Bank Information Center Issues Briefing (September), available at http:// www.bicusa.org (30 May, 2003).

Barnett, Michael and Martha Finnemore (1999) 'The Politics, Power, and Pathologies of International Organizations', International Organization 53(4): 699-732.

Barnett, Michael and Martha Finnemore (2004) Rules for the World: International Organizations in Global Politics, Ithaca, NY: Cornell University Press.

Bebbington, Anthony, Scott Guggenheim, Elizabeth Olson and Michael Woolcock (2004) 'Exploring Social Capital Debates at the World Bank', Journal of Development Studies 40(5): 33-64.

Bøås, Morten and Desmond McNeill, eds (2004) Global Institutions and Development: Framing the World?, London and New York: Routledge.

Caufield, Catherine (1996) Masters of Illusion: The World Bank and the Poverty of Nations, New York: Henry Holt \& Co.

Checkel, Jeffrey, ed (2005) 'International Institutions and Socialization in Europe', International Organization 59(4): 801-1079.

Cooley, Alexander and James Ron (2002) 'The NGO Scramble: Organizational Insecurity and the Political Economy of Transnational Action', International Security 27(1): 5-39.

Crane, Barbara B. and Jason L. Finkle (1981) 'Organizational Impediments to Development Assistance: The World Bank's Population Program', World Politics 33(4): 516-33.

Einhorn, Jessica (2001) 'The World Bank's Mission Creep', Foreign Affairs 80(5): 22-35.

Einhorn, Jessica (2006) 'Reforming the World Bank', Foreign Affairs 85(1): 17-22. 
Fearon, James and Alexander Wendt (2002) 'Rationalism vs. Constructivism: A Skeptical View', in Walter Carlsnaes, Thomas Risse and Beth Simmons, eds, The Handbook of International Relations, 52-72, London: Sage.

Finnemore, Martha (1996) National Interests in International Society, Ithaca, NY: Cornell University Press.

Finnemore, Martha and Kathryn Sikkink (1998) 'International Norms Dynamics and Political Change', International Organization 52(4): 887-917.

Fox, Jonathan A. and L. David Brown, eds (1998) The Struggle for Accountability: The World Bank, NGOs, and Grassroots Movements, Cambridge, MA: MIT Press.

Goldman, Michael (2005) Imperial Nature: The World Bank and Struggles for Social Justice in the Age of Globalization, New Haven, CT: Yale University Press.

Gould, Erica (2006) 'Delegating IMF Conditionality: Understanding Variations in Control and Conformity', in Darren Hawkins, David A. Lake, Daniel L. Nielson and Michael J. Tierney, eds, Delegation and Agency in International Organizations, Cambridge: Cambridge University Press (forthcoming).

Haas, Ernst B. (1990) When Knowledge Is Power: Three Models of Change in International Organizations, Berkeley, CA: University of California Press.

Haas, Peter M. and Ernst Haas (1995) 'Learning to Learn: Improving International Governance', Global Governance 1: 255-85.

Haas, Peter M. and Ernst Haas (2002) 'Pragmatic Constructivism and the Study of International Institutions', Millennium: Journal of International Studies 31(3): 573-601.

Hamlet, Lawrence (2004) 'Assessing the Impact of Organizational Culture on International Organizations', Mimeo, Annual Meeting of ISA, Montreal, 19 March.

Hawkins, Darren, David A. Lake, Daniel L. Nielson and Michael J. Tierney (2006) 'States, International Organizations and Principal Agent Theory', in Darren Hawkins, David A. Lake, Daniel L. Nielson and Michael J. Tierney, eds, Delegation and Agency in International Organizations, Cambridge: Cambridge University Press (forthcoming).

Jupille, Joseph, James Caporaso and Jeffrey Checkel (2003) 'Integrating Institutions: Rationalism, Constructivism and the Study of the European Union', Comparative Political Studies 36(1-2): 7-40.

Kapur, Devesh (2000) 'Processes of Change in International Organizations', Mimeo, Cambridge, MA: Harvard University, Weatherhead Center for International Affairs.

Kardam, Nuket (1993) 'Development Approaches and the Role of Policy Advocacy: The Case of the World Bank', World Development 21(11): 1773-86.

Kiewiet, D.Roderick and Mathew D. McCubbins (1991) The Logic of Delegation: Congressional Parties and the Appropriations Process, Chicago, IL: University of Chicago Press.

Koremenos, Barbara, Charles Lipson and Duncan Snidal (2001) 'The Rational Design of International Institutions', International Organization 55(4): 761-99.

Lake, David (2002) 'Progress in International Relations: Beyond Paradigms in the Study of Institutions', in Michael Brecher and Frank Harvey, eds, Realism and Institutionalism in International Studies, 135-52, Ann Arbor, MI: University of Michigan Press.

Lake, David and Matthew McCubbins (2006) 'The Logic of Delegation to International Organizations', in Darren Hawkins, David A. Lake, Daniel L. Nielson and Michael J. Tierney, eds, Delegation and Agency in International Organizations, Cambridge: Cambridge University Press (forthcoming).

Legro, Jeffrey (1996) 'Culture and Preferences in the International Cooperation Two-Step', American Political Science Review 90(1): 118-37.

Leiteritz, Ralf (2005) 'Explaining organizational outcomes: the International Monetary Fund and capital account liberalization', Journal of International Relations and Development 8(1): 1-26.

Lupia, Arthur and Mathew D. McCubbins (1998) The Democratic Dilemma: Can Citizens Learn What They Need to Know?, New York: Cambridge University Press. 
Mallaby, Sebastian (2004) The World's Banker: A Story of Failed States, Financial Crises, and the Wealth and Poverty of Nations, New York: Penguin Press.

Martens, Bertin (2002) The Institutional Economics of Foreign Aid, New York: Cambridge University Press.

McIntosh, Mary, Anni Poikolainen, Kimberly Hewitt, Tara Lubin, Kathlen Knoll, Elizabeth McGaha and Jean D'Amico (2003) The Global Poll: Multinational Survey of Opinion Leaders 2002, Washington, DC: Princeton Survey Research Associates for the World Bank.

Miller-Adams, Michelle (1999) The World Bank: New Agendas in a Changing World, London and New York: Routledge.

Momani, Bessma (2005) 'Limits on Streamlining Fund Conditionality: The International Monetary Fund's Organizational Culture', Journal of International Relations and Development 8(2): $142-63$.

Nielson, Daniel L. and Michael J. Tierney (2003) 'Delegation to International Organizations: Agency Theory and World Bank Environmental Reform', International Organization 57(2): $241-76$.

Nielson, Daniel L. and Michael J. Tierney (2005) 'Theory, Data, and Hypothesis Testing: World Bank Reform Redux', International Organization 59(3): 785-800.

Operations Evaluation Department (2001a) 'Annual Review of Development Effectiveness 2000: From Strategy to Results', Washington, DC: World Bank, available at http://www.worldbank. org/oed (30 May, 2003).

Operations Evaluation Department (2001b) 'OED Review of the Bank's Performance on the Environment', Washington, DC: World Bank, available at http://www.worldbank.org/oed (30 May, 2003).

Operations Evaluation Department (2002) '2000-2001 Annual Report on Operations Evaluation', Washington, DC: World Bank, available at http://www.worldbank.org/oed (30 May, 2003).

Park, Susan (2005) 'Norm Diffusion within International Organizations: A Case Study of the World Bank', Journal of International Relations and Development 8(2): 111-41.

Pincus, Jonathan and Jeffrey Winters (2002) Reinventing the World Bank, Ithaca, NY: Cornell University Press.

Portfolio Management Task Force (1992) Effective Implementation: Key to Development Impact, Washington, DC: World Bank.

Quality Assurance Group (1997) 'Portfolio Investment Program: Draft Reviews of Sector Portfolio and Lending Instruments', Internal memo, on file with authors, Washington, DC: World Bank.

Quality Assurance Group (2001) Annual Report on Portfolio Performance Fiscal Year 2001, Washington, DC: World Bank.

Rich, Bruce (1994) Mortgaging the Earth, Boston, MA: Beacon Press.

Rich, Bruce (2002) 'The World Bank under James Wolfensohn: The Smile on a Child's Face', in Jonathan Pincus and Jeffrey Winters, eds, Reinventing the World Bank, 26-53, Ithaca, NY: Cornell University Press.

Schein, Edgar H. (1992) Organizational Culture and Leadership, San Francisco, CA: Jossey-Bass.

Sending, Ole Jacob (2002) 'Constitution, Choice and Change: Problems with the "Logic of Appropriateness" and its Use in Constructivist Theory', European Journal of International Relations 8(4): 443-70.

Snidal, Duncan (2002) 'Rational Choice and International Relations', in Walter Calsnaes, Thomas Risse and Beth Simmons, eds, The Handbook of International Relations, 73-94, London: Sage.

Swidler, Ann (1986) 'Culture in Action: Symbols and Strategies', American Sociological Review 51(2): 273-86.

Tendler, Judith (1975) Inside Foreign Aid, Baltimore, MD: Johns Hopkins University Press. 
Tierney, Michael and Catherine Weaver (2005) 'Principles and Principals: The Possibilities for Theoretical Synthesis and Scientific Progress in the Study of International Organizations',Paper presented at the 2005 ISA Annual Meeting, Honolulu.

Udall, Lori (1998) 'The World Bank and Public Accountability: Has Anything Changed?', in Jonathan Fox and L. David Brown, eds, The Struggle for Accountability: The World Bank, NGOs, and Grassroots Movements, 391-436, Cambridge, MA: MIT Press.

Wade, Robert (1997) 'Greening the Bank: The Struggle over the Environment, 1970-1995', in Devesh Kapur, John P. Lewis and Richard Webb, eds, The World Bank: Its First Half Century - Volume 2: Perspectives, 611-734, Washington, DC: Brookings Institution Press.

Weaver, Catherine (2005) The Poverty of Reform: The Rhetoric, Reality and Reform of the World Bank, Lawrence, KS: University of Kansas, Department of Political Science, mimeo.

Wilks, Alex (2001) 'Overstretched and Underloved: World Bank Faces Strategy Decisions', available at http://www.brettonwoodsproject.org/topic/reform/index.html (3 April, 2006).

Winters, Jeffrey (2002) 'Criminal Debt', in Jonathan Pincus and Jeffrey Winters, eds, Reinventing the World Bank, 101-30, Ithaca, NY: Cornell University Press.

World Bank (1987) 'The Culture of the World Bank and its Implications for the Reorganization Process', Internal memo, on file with authors, Washington, DC: World Bank.

World Bank (1997a) Social Development and Results on the Ground: Task Group Report, Washington, DC: World Bank.

World Bank (1997b) The Strategic Compact: Renewing the Bank's Effectiveness to Fight Poverty, Washington, DC: World Bank.

World Bank (2001a) Design and Management of Technical Assistance in the PREM Portfolio: Stocktaking and Lessons Learned, Washington, DC: World Bank.

World Bank (2001b) 'Assessment of the Strategic Compact', Washington, DC: World Bank, available at http:/www.worldbank.org/html/extdr/strategypapers/assessment.pdf (2 January, 2002).

\section{About the Authors}

Daniel L. Nielson is Associate Professor of Political Science and Associate Chair at Brigham Young University. His current research examines domestic and international factors influencing reform efforts in developing countries. $\mathrm{He}$ is co-editor of Delegation and Agency in International Organizations (Cambridge University Press, 2006), and has published in numerous journals including International Organization, American Journal of Political Science, Comparative Political Studies, and Party Politics. He is completing a book manuscript entitled Electing to Develop: The Political Economy of Reform in Middle-Income Democracies.

Michael J. Tierney is Assistant Professor of Government at the College of William and Mary. His current research examines the delegation of authority to international organizations and the causes of foreign aid allocations. He is co-editor of Delegation and Agency in International Organizations (Cambridge University Press, 2006), and co-author of Greening Aid? Understanding Environmental Assistance to Developing Countries (Oxford University Press, forthcoming 2007). 
Catherine E. Weaver is Assistant Professor of Political Science at the University of Kansas. Her current research examines the hypocrisy of international organizations and the relationship between organizational culture and change. She has previously published in Global Governance and is currently completing a book manuscript entitled The Poverty of Reform: The Rhetoric and Reality of the World Bank. 